Background and aims Type 1 diabetes (T1D) is an autoimmune disease that results from the progressive and selective destruction of pancreatic beta cells. Trace elements have a key role as well as in adaptive immunity in inflammatory processes. The aim of this study was to measure circulating levels of Zinc (Zn), Copper $(\mathrm{Cu})$, and protein fractions in patients with T1D.

Methods Sixty (60) subjects aged less than 15 years, divided into two similar groups ( 30 with recently type 1 diabetes and 30 controls) were recruited in the Department of Paediatrics of Tlemcen University Hospital. Zinc and copper were measured by polarimetry. The protein fractions were measured by zone electrophoresis on cellulose acetate (PFIC, serum protein electrophoresis) (HELENA, USA).

Results Serum $\mathrm{Zn}$ and $\mathrm{Cu}$ levels were significantly elevated in type 1 diabetes compared with controls (respectively, $\mathrm{p}=0.001$, $\mathrm{p}=0.002$ ). 0,05)." > However, the percentage of alpha -1 , alpha -2 , beta and gamma globulins, and the total rate of serum globulins were identical in the two groups $(p>0.05)$. Conversely, the percentage of albumin and albumin/globulin ratio were significantly decreased in type 1 diabetes compared with controls $(\mathrm{p}<$ 0.01 and $\mathrm{p}<0.05$, respectively).

Conclusion Disorders $\mathrm{Zn}$ and $\mathrm{Cu}$ could be significant immunological abnormalities and inflammatory signs at the beginning of the installation of T1D.

\section{PO-0052 NITRIC OXIDE, IMMUNOGLOBULINS AND LIPID PEROXIDATION IN TYPE 1 DIABETIC CHILDREN}

${ }^{1} \mathrm{M}$ Smahi, ${ }^{2} \mathrm{M}$ Aribi, ${ }^{2} \mathrm{~L}$ Ysmaildahlok, ${ }^{2} \mathrm{~L}$ Hamouda, ${ }^{2} \mathrm{~W}$ Meziane. ${ }^{1}$ Pediatrics and Neonatology, Mother-Child University Hospital Tlemcen, Tlemcen, Algeria; ${ }^{2}$ University of Tlemcen, Laboratory of Applied Molecular Biology and Immunology, Tlemcen, Algeria

\subsection{6/archdischild-2014-307384.725}

Background and aims To assess the levels of lipid peroxidation and circulating levels of nitric oxide (NO), lipoproteins and immunoglobulins in type 1 diabetes children.

Methods Thirty (30) type 1 diabetic patients newly diagnosed and 30 healthy control subjects, comparable for age (less than 15 years), sex and body mass index (BMI) were recruited in the Department of Paediatrics in the Mother and Child Hospital of Tlemcen. Lipid peroxidation was assessed by measuring the levels of malondialdehyde (MDA, $\mathrm{CH} 2$ (CHO) 2) using the thiobarbituric acid (TBA). The serum NOx (nitrate and nitrite, NOx [NO2-, NO3-]) was measured as an indirect marker of the formation of $\mathrm{NO}$ in vivo by the Griess method. Lipoproteins were measured by ultrasensitive gel electrophoresis (SEBIA, France). Immunoglobulins were determined by the radial immunodiffusion technique (IDR).

Results Circulating levels of MDA and NO production were significantly higher in type 1 diabetic patients compared to controls (respectively, $\mathrm{p}=0.001, \mathrm{p}=0.01)$. This was also the same for immunoglobulins $A, G$ and $M$ (for all comparisons, $p<0.01$ ). Circulating levels of alpha lipoprotein and Lp (a) were similar in both groups $(p>0.05)$; however, those of the pre-beta and beta lipoproteins were significantly increased in patients compared to controls (respectively, $\mathrm{p}=0.039, \mathrm{p}=0.018$ ).

Conclusion The onset of the DT1 is associated with nitrogen stress and oxidation of circulating lipids. Also, the excessive formation of NO and MDA may be the result of inflammatory conditions associated with the autoimmune disease process.

\section{PO-0053 HEALTH AFFECTING BEHAVIOUR CHANGES IN ADOLESCENTS WITH TYPE 1 DIABETES MELLITUS}

V Bulikaite, V Grigaliuniene, A Vaskelyte. Nursing and Care, Lithuanian University of Health Sciences, Kaunas, Lithuania

\subsection{6/archdischild-2014-307384.726}

Background Is very important to teach the patien with diabetes to live together with this incurable disease so they avoid late complications. The transference of knowledge to a patient does not always change his/her behaviour.

The aim To analyse changes of adolescents diabetes habits of nutrition, physical activity, smoking, and usage of alcohol before contracting diabetes and when 3,6 and 12 month pass after the contraction of diabetes.

Material and methods The study was conducted in Children Endocrinology department, Hospital of Kaunas University of Medicine. 50 adolescents of 13-17 years old with diabetes participated in anonymous questionnaire survey. Pre-test and posttest design was used to conduct the study. The Wilcoxon's paired sample test was used to determine the difference in groups.

Results The study revealed that $41 \%$ who participated in the study did not eat regular, 22\% did not attend any sports, 53\% of adolescents were smoking and $40 \%$ of the surveyed were taking alcohol before contracting diabetes. When 3 months passed after the diagnosis of diabetes, the number of patients eating regular significantly increased, 89\% not doing any sports, 16\% were smoking, $12 \%$ admitted they were taking alcohol. After 6 and 12 months patients behaviour was changed $(p<0,05)$.

Conclusion Three months after diagnosis of diabetes mellitus most of adolescents ate regularly, there were less of those who smoked, consumed alcohol and the lowest number of those who exercised when compared with findings of surveys conducted before diagnosis and after six or twelve months.

\section{PO-0054 EPIDEMIOLOGY OF TYPE 1 DIABETES MELLITUS IN CHILDREN IN TUNISIA}

${ }^{1} \mathrm{M}$ Hachicha, ${ }^{1} \mathrm{H}$ Aloulou, 'L Sfaihi, ${ }^{2} \mathrm{~S}$ Ben Becher, ${ }^{2} \mathrm{KH}$ Bousetta, ${ }^{3} \mathrm{~N}$ Gandoura, ${ }^{4} \mathrm{~N}$ Gueddiche, ${ }^{5} \mathrm{~T}$ Gargah, ${ }^{6} \mathrm{~N}$ Tbib, ${ }^{7} \mathrm{~L}$ Boughammoura, ${ }^{8} \mathrm{~A}$ Harbi, ${ }^{9} \mathrm{~K}$ Habbouli, ${ }^{10} \mathrm{~T}$ Sfar, ${ }^{11} \mathrm{~A}$ Bouziri, ${ }^{12} \mathrm{~N}$ Bouziri, ${ }^{13} \mathrm{~F}$ Bayoudh, ${ }^{14} \mathrm{~A}$ Chouaibi, , ${ }^{15} \mathrm{H}$ Ben Ameur, ${ }^{16} \mathrm{~S}$ Yaich, ${ }^{1} \mathrm{TH}$ Kammoun. ${ }^{1}$ Pediatrics, Hédi Chaker University Hospital, Sfax, Tunisia; ' $P$ Pediatrics, Children's Hospital, Tunis, Tunisia; ${ }^{3}$ Pediatrics, Bizerte Hospital, Bizerte, Tunisia; ${ }^{4}$ Pediatrics, Monastir Hospital, Monastir, Tunisia; ${ }^{5}$ Pediatrics, Charle Nicolle Hospital, Tunis, Tunisia; ${ }^{6}$ Pediatrics, Rabta Hospital, Tunis, Tunisia; ${ }^{7}$ Pediatrics, Farhat Hachd Hospital, Sousse, Tunisia; ${ }^{8}$ Pediatrics, Sahloul Hospital, Sousse, Tunisia; ${ }^{9}$ Pediatrics, Kairouan Hospital, Kairouen, Tunisia; ${ }^{10}$ Pediatrics, Mahdia Hospital, Mahdia, Tunisia; ${ }^{11}$ Pediatrics, Nabeul Hospital, Nabeul, Tunisia; ${ }^{12}$ Pediatrics, Jerba Hospital, Jerba, Tunisia; ${ }^{13}$ Pediatrics, Miltaire Hospital, Tunis, Tunisia; ${ }^{14}$ Pediatrics, Sidi Bouzid Hospital Hospital, Sidi Bouzid, Tunisia; ${ }^{15}$ Pediatrics, Gafsa Hospital, Gafsa, Tunisia; ${ }^{16}$ Community and Preventive Medecine, Hédi Chaker University Hospital, Sfax, Tunisia

\subsection{6/archdischild-2014-307384.727}

Introduction The geographical incidence of type 1 diabetes mellitus in children varies widely worldwide. Both genetic and environmental factors have been implicated.

Objective Evaluated the incidence of type 1 diabetes in children in Tunisia and identified the epidemiologic characteristics.

Patients and methods We conducted a retrospective study of new cases of type 1 diabetes in children $(0-15)$ years, discovered during the years 2009-2010-2011 in 17 paediatric centre from Tunisia.

We divided our patients into 3 groups: group 1 (0-4 years), Group 2 (5-9 years) and group 3 (10-15 years). These three 